\title{
RESEARCH OF THE OPTIMUM SCALE OF STANDARD SECTIONS OF AGRICULTURAL PURPOSE LINES
}

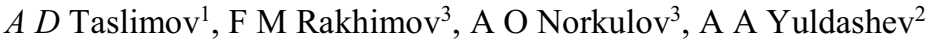 \\ ${ }^{1}$ Tashkent state technical university, University street №2, Tashkent, 100095, Uzbekistan \\ ${ }^{3}$ Navoi State Mining Institute, Uzbekistan \\ ${ }^{2}$ Karakalpak State University, 230100, Uzbekistan, Nukus, Ch. Abdirov St. 1
}

\begin{abstract}
In the article, for the optimal development of networks, the parameter of the network element is selected from the existing standard scale of standard sizes and the scale of standard sections of lines (cables) is optimized or their optimality is checked.
\end{abstract}

\section{Introduction}

For the optimal development of networks, it is important not only to select the optimal parameter of a network element from the existing standard scale (parametric series) of standard sizes, but also to optimize standard scales of equipment standard sizes or to check their optimality. At the same time, the standard scale of cable cross-sections does not meet the requirements of [1-5], and therefore the question arises as to whether the existing scale of cable cross-sections corresponds to the optimality requirements.

Since cable lines have not yet found widespread use in rural areas, there are conditions not only for checking the optimality of the existing scale of cable cross-sections, but also for establishing the optimal scale of cable conductor cross-sections intended for the construction of cable power lines in rural areas (if the existing scale is not meets the optimality conditions).

To construct a parametric series of sections of lines (cables) intended for cable power lines in rural areas, it is proposed to use the method of economic load intervals [610]. This method uses the principle of limiting the allowable increase in costs from the optimal ones. As an optimality criterion, it assumes the use of a minimum of total costs [11-15].

When establishing the optimal scale for equipment standard sizes, it is important to determine the initial and final value of the scale standard size. The initial cable section is mainly determined by the minimum loads. The final cross-section of the cables is determined by the highest actual current loads or the highest possible shortcircuit currents.

For cables of rural electrical networks for long-term permissible current loads, the final cross-section can be chosen at least $75 \mathrm{~mm}^{2}$, and under the conditions of thermal stability, the cross-section must be at least 100 $\mathrm{mm}^{2}$. Thus, based on the analysis carried out for rural cable power lines, it is necessary to take the final section of the scale equal to $120 \mathrm{~mm}^{2}$, and the initial section must be established in the course of research [16-18].

In the practice of design and scientific and technical research, it is accepted that two compared options are considered economically equivalent if their indicators differ by no more than $3-5 \%$. This condition is the basis for one of the approaches to determining the optimal parametric series, which is that the deviation of the actual costs when using a section from the standard scale from the optimal is $3-5 \%$ [19-21].

The deviation of the actual costs when using the optimal section from the standard scale is determined by:

$$
3_{\phi}=(1+\delta) 3_{\ni}
$$

where $\delta$ is the deviation of the actual costs from the optimal ones, taken equal to 0.03-0.05.

The relative change in costs is:

$$
\delta_{i}^{\mathrm{H}}=\frac{3_{i}^{\mathrm{H}}-3_{i \ni}^{\mathrm{H}}}{3_{i \ni}^{\mathrm{H}}} \quad \text { And } \quad \delta_{i}^{\mathrm{B}}=\frac{3_{i}^{\mathrm{B}}-3_{i \ni}^{\mathrm{B}}}{3_{i \ni}^{\mathrm{B}}}
$$

or

$$
\delta_{i}^{\mathrm{H}}=\frac{\left(\sqrt{F_{i}}-\sqrt{F_{i-1}}\right)^{2}}{\frac{K_{0}}{k}+2 \sqrt{F_{i-1} F_{i}}} \quad \text { And } \quad \delta_{i}^{\mathrm{B}}=\frac{\left(\sqrt{F_{i+1}}-\sqrt{F_{i}}\right)^{2}}{\frac{K_{0}}{k}+2 \sqrt{F_{i} F_{i+1}}}
$$

From (2) and (3) it follows that the value of the relative deviation of total costs when deviating from the economic section is determined only by the ratio of adjacent standard sections and the ratio of the constant component of the line cost $K_{0}$, which does not depend on the section, to the rise in price $k$. Analysis of the data in Table 1 shows that the value of the ratio $K_{0} / k$ varies within narrow limits - from 92.73 to 124.02 with the arithmetic mean of 116.62 and the mean square of 112.27. The calculated values $\delta_{i}^{\mathrm{B}}$ are given in table. 1 . 
Thus, taking into account the permissible (3-5\%) deviation of actual costs from economic costs allows us to abandon the use of some sections from the standard series (Fig. 1), which confirms the relevance and legitimacy of raising the question of the expediency of the existing scale of nominal cable cross-sections and the need to develop a new scale satisfying the conditions of economy.

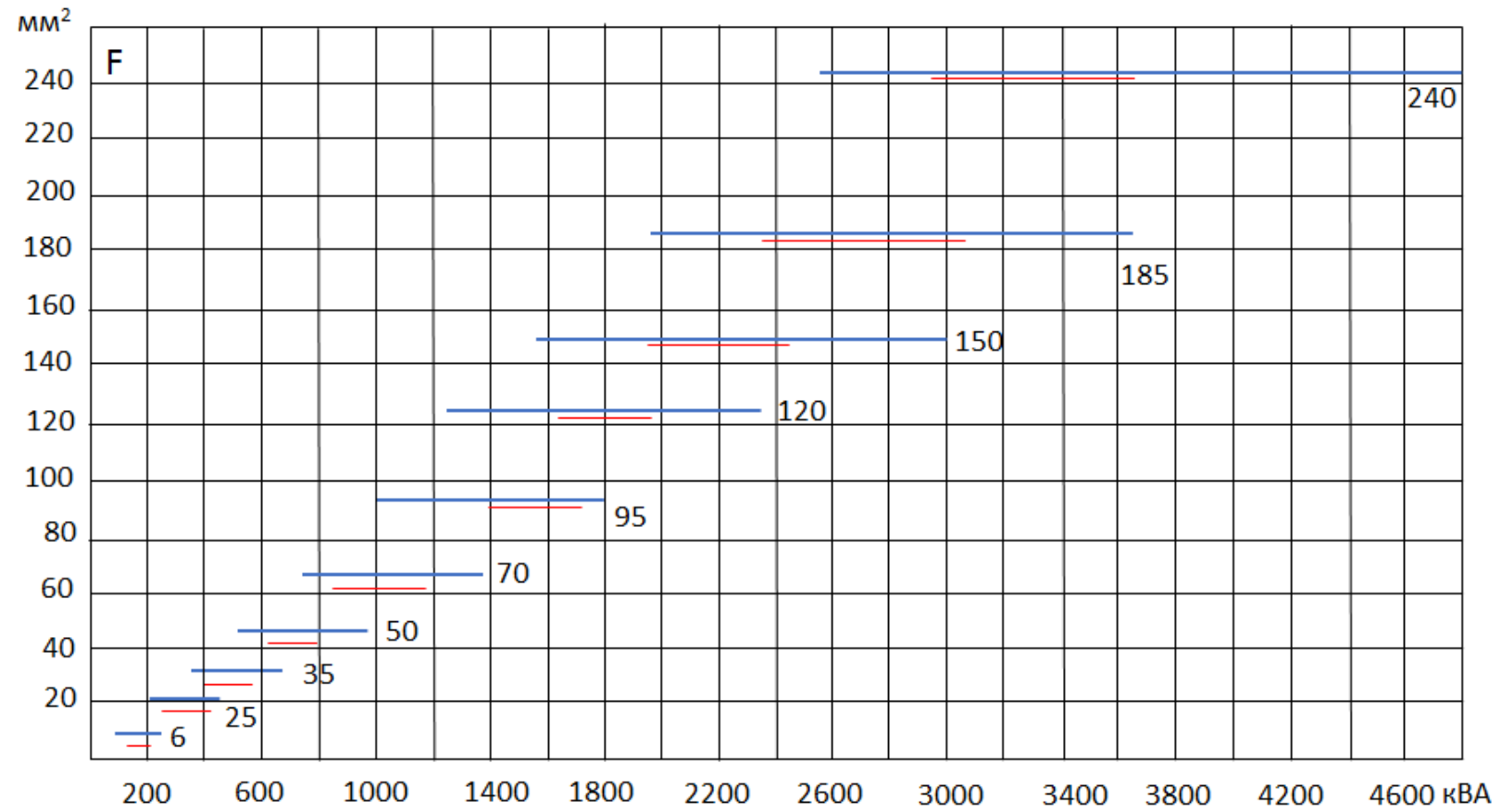

Fig. 1. Change in economic load intervals at.

Table 1

The magnitude of the relative changes in costs when deviating from the economic section

\begin{tabular}{|c|c|c|c|c|c|c|c|c|}
\hline $\begin{array}{c}\text { Section } \\
\mathrm{mm}^{2}\end{array}$ & \multicolumn{9}{|c|}{ Relative change in costs with $K_{0} / k$} \\
\cline { 2 - 9 } & 97,22 & 118,90 & 92,73 & 115,92 & 124,02 & 120,91 & 112,27 & 116,62 \\
\hline 16 & 0,0073 & 0,0063 & 0,0075 & 0,0064 & 0,0061 & 0,0062 & 0,0066 & 0,0064 \\
\hline 25 & 0,0054 & 0,0047 & 0,0055 & 0,0048 & 0,0046 & 0,0047 & 0,0049 & 0,0048 \\
\hline 35 & 0,0074 & 0,0066 & 0,0076 & 0,0067 & 0,0064 & 0,0065 & 0,0068 & 0,0067 \\
\hline 50 & 0,0078 & 0,0071 & 0,0080 & 0,0072 & 0,0069 & 0,0070 & 0,0073 & 0,0071 \\
\hline 70 & 0,0073 & 0,0068 & 0,0074 & 0,0068 & 0,0066 & 0,0067 & 0,0069 & 0,0068 \\
\hline 95 & 0,0047 & 0,0044 & 0,0048 & 0,0044 & 0,0043 & 0,0044 & 0,0045 & 0,0044 \\
\hline 120 & 0,0046 & 0,0043 & 0,0046 & 0,0044 & 0,0043 & 0,0043 & 0,0044 & 0,0043 \\
\hline 150 & 0,0043 & 0,0041 & 0,0043 & 0,0041 & 0,0040 & 0,0040 & 0,0041 & 0,0041 \\
\hline 185 & 0,0069 & 0,0066 & 0,0070 & 0,0067 & 0,0066 & 0,0066 & 0,0067 & 0,0066 \\
\hline
\end{tabular}

At present, it is recommended to build a standard series of standard sizes with a constant step according to the principle of arithmetic or geometric progression [6]. The existing number of cross-sections roughly obeys the principle of geometric progression. Then you can write.

$$
\frac{F_{i+1}}{F_{i}}=q
$$

Or the scale step value is determined

$$
\frac{F_{i+1}}{F_{i}}=q
$$

From the obtained expression (5) it can be seen that the size of the scale step is determined only by the value of the relative change in costs when deviating from the economic section and the ratio of the constant component of the cost of the line, which does not depend on the section, to the coefficient of rise in the cost of the line, and 
also on the initial section of the scale. The dependence of the increment of the scale $F_{0}$ on the change $\frac{K_{0}}{k}$ in the initial section of the scale and the ratio is shown graphically in Fig. 2. The curves in fig. 2a. plotted at $F_{0}=16 \mathrm{~mm}^{2}$, and in Fig. $2 \mathrm{~b}$ - for $\delta=0,05$ and $\frac{K_{0}}{k}=112,27$.

In this case, the step size of the cable cross-section scale is $3.48 ; 2.97$ and 2.63, respectively, for initial sections of 10.16 and $25 \mathrm{~mm}^{2}$. In this case, instead of 8 standard sections, it is possible to use only three sections. In this case, after rounding off the scale of sections, they take the form: $10,35,120 \mathrm{~mm}^{2} ; 16,50,150 \mathrm{~mm}^{2} ; 25,70$, $150 \mathrm{~mm}^{2}$ [22-25].

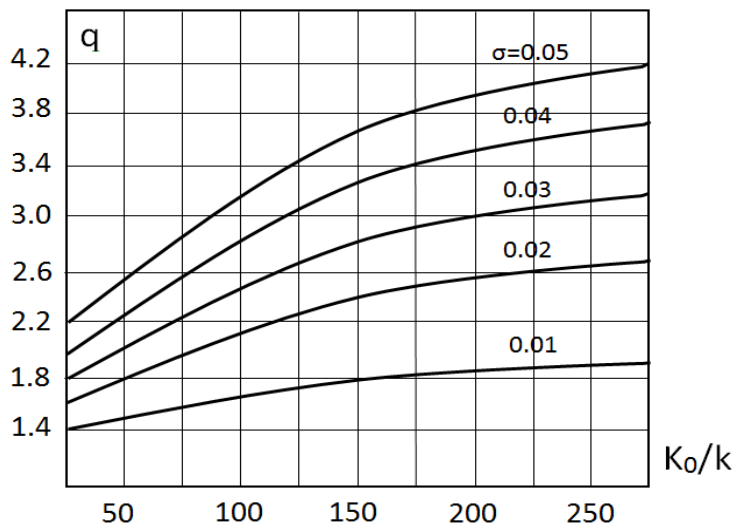

a)

Fig. 2. Dependence of the scale step on the change, $\frac{\boldsymbol{K}_{\mathbf{0}}}{\boldsymbol{k}}, \boldsymbol{F}_{\mathbf{0}}$, and $\boldsymbol{\delta}$
The calculation of the reduction of energy losses in cable lines due to the use of a limited number of standard cable cross-sections is carried out. The calculations were carried out for the regions of the SES of the Tashkent region. In this case, reducing the number of cable crosssections used in electrical networks can significantly reduce power losses. At the same time, the reduction in specific electricity losses is $15 \mathrm{kWh}$ per $1 \mathrm{~kW}$ of load on the buses of $10 / 0.38 \mathrm{kV}$ transformer substations, which for one region is $427,500 \mathrm{kWh}$ per year of electricity [2627].

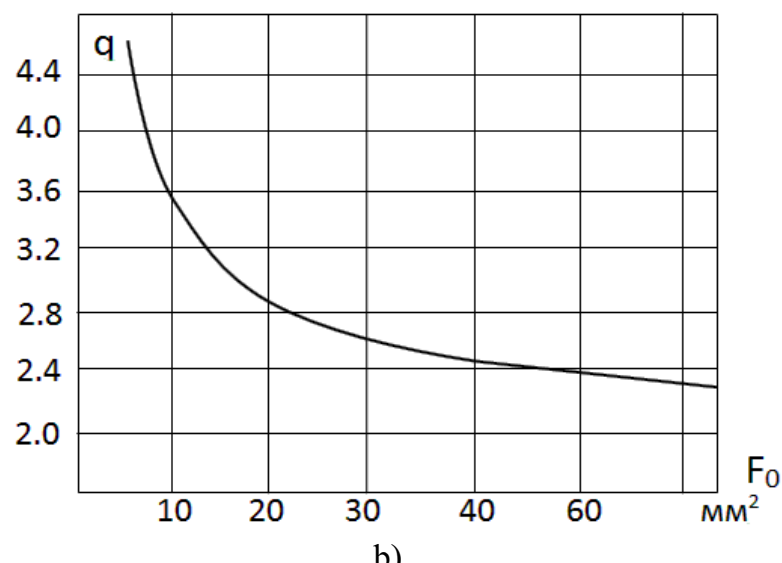

b)
Thus, the existing scale of nominal cable crosssections does not satisfy the conditions for optimal use of cable lines in rural areas and contains an overestimated number of cross-sections. Based on the analysis, the final cross-section of the cables was determined and the optimal value of the initial cross-section of the scale was established. In this case, the optimal number of crosssections in the scale of nominal cross-sections of cables for agricultural cable lines is: $25 ; 50 ; 120 \mathrm{~mm}^{2}$.

\section{References}

1. Calculation of power transmission lines for agricultural purposes: a textbook for students p. $\mathrm{x}$. universities // G.I. Yanukovich 2nd ed., add. - Minsk: BGATU, 2004 .- 105p.

2. Zuev E.N., Efentiev S.N. The tasks of choosing economically feasible sections of wires and cables: textbook. allowance. M .: MEI, 2005 .- 88p.

3. Taslimov A.D., Shaimatov B.Kh., Kholmurodov M.B. Unification of cable cross-sections for distribution electrical networks taking into account the growth of loads. International scientific and technical conference "Modern techniques and technologies of the mining and metallurgical industry and ways of their development" / Navoi, 2013. - pp. 147-149.

4. Saidkhodjaev A G, Najimova A M and Bijanov A K 2019 Method for determining the maximum load of consumers in city power supply systems E3S Web Conf 139 doi:10.1051/e3sconf/201913901078.
5. Taslimov A D, Rakhmonov I U 2019 Optimization of complex parameters of urban distribution electric networks Journal of Physics: Conference Series 1399 doi:10.1088/1742-6596/1399/5/055046

6. Rakhmonov I U, Niyozov N N 2019 Optimization setting of steel-smelting industry in the issue of alloy steels E3S Web Conf 139 doi:10.1051/e3sconf/201913901077

7. Rakhmonov I U, Reymov K M and Shayumova Z M 2019 The role information in power management tasks. E3S Web Conf 139 doi:10.1051/e3sconf/201913901080

8. Rakhmonov I U, Tovbaev A N, Nematov L A and Alibekova T Sh 2020 Development of forecasted values of specific norms for the issues of produced products in industrial enterprises Journal of Physics: Conference Series 1515 doi:10.1088/1742-6596/1515/2/022050

9. Rakhmonov I U, Nematov L A, Niyozov N N, Reymov K M and Yuldoshev T M 2020 Power consumption management from the positions of the general system theory Journal of Physics: Conference Series 1515 doi:10.1088/1742-6596/1515/2/022054

10. Rakhmonov I U, Reymov K M, Najimova A M, Uzakov B T and Seytmuratov BT 2019 Analysis and calculation of optimum parameters of electric arc furnace Journal of Physics: Conference Series 1399 doi:10.1088/1742-6596/1399/5/055048

11. Taslimov A D, Berdishev A S, Melikuzuev M V and Rakhimov F M 2019 Method of selecting parameters of cable lines distributive networks $10 \mathrm{kv}$ in uncertainty 
$\begin{array}{lllll}\text { conditions } & \text { E3S } & \text { Web } & \text { Conf } & 139\end{array}$ doi:10.1051/e3sconf/201913901082

12. Taslimov A D, Berdishev A S, Melikuziyev M V and Rakhimov F M 2019 Method of choosing the unification of cable sections of electric network cables under conditions of load development uncertainty E3S Web Conf 139 doi:10.1051/e3sconf/201913901081

13. Rakhmonov, I.U., Berdishev, A.A., Khusanov, B.M., Khaliknazarov, U., Utegenov, U. (2020) General characteristics of networks and features of electricity consumers in rural areas Journal of IOP: Conference Series. MIP: Engineering-2020. 883 (2020) 012104 doi:10.1088/1757-899X/883/1/012104

14. Karimov R.Ch., Shamsiyev K., and others. IOP Conf. Series: Materials Science and Engineering, 883(1), 012142, (2020). doi:10.1088/1757-899X/883/1/012142

15. Karimov R.Ch., Shamsiyeva N. and others. IOP Conf. Series: Materials Science and Engineering, 883(1), 012120, (2020). doi:10.1088/1757-899X/883/1/012120

16. E.G.Usmanov, A.N.Rasulov, M.K.Bobojanov, R.Ch.Karimov. E3S Web of Conferences 139, 01079 (2019), doi.org/10.1051/e3sconf/201913901079

17. Bobojanov M.K., Rasulov A.N., Karimov R.Ch., Sattarov H.A. Bulletin Descendants of Mohammed AlKhwarizmi (ISSN: 2181-9211), Tashkent, 3(5), - PP.106109, (2018).

18. Burievich, T.J. The questions of the dynamics of drilling bit on the surface of well bottom// Arch. Min. Sci. -Poland. - Vol. 61 (2016). - №2. - P. 279-287. DOI 10.1515/amsc-2016-0020.

$19 . \quad$ Toshniyozov, L.G., Toshov, J.B. Theoretical and experimental research into process of packing in drilling// Mining Informational and Analytical Bulletin Volume 2019, Issue 11, 2019, Pages 139-151. DOI: 10.25018/0236-1493-2019-11-0-139-151.

20. Azamatovich, A.N., Amrillo, M.B, Burievich, T.J., Umarxanoxich, J.R., Shavkatovich, Z.A. A complex of methods for analyzing the working fluid of a hydrostatic power plant for hydraulic mining machines / International Journal of Advanced Science and Technology. Volume 29, Issue 5 Special Issue, 28 March 2020, Pages 852-855

21. Hoshimov, F.A., Bakhadirov, I.I., Erejepov, M., Djumamuratov, B. (2019) Development of method for normalizing electricity consumption E3S Web Conf 139 doi:10.1051/e3sconf/201913901074

22. G.R.Rafikova, M.R.Ruzinazarov, S.K.Makhmutkhonov. E3S Web of Conferences, 139, 01075 , https://doi.org/10.1051/e3sconf/201913901075

23. Safarov J.E., Sultanova Sh.A., Dadayev G.T., Samandarov D.I. Method for drying fruits of rose hips. // International Journal of Innovative Technology and Exploring Engineering. Vol.9, Iss.1. 2019. P.3765-3768,. 24. Safarov J.E., Sultanova Sh.A., Dadayev G.T., Samandarov D.I. Method for the primary processing of silkworm cocoons (Bombyx mori). // International Journal of Innovative Technology and Exploring Engineering. Volume-9, Issue-1, November, 2019. P.4562-4565.

25. Safarov J.E., Sultanova Sh.A., Dadayev G.T. Development of solar accumulating drying equipment based on the theoretical studies of solar energy accumulation. Energetika. Proc. CIS Higher Educ. Inst. and Power Eng. Assoc. V. 63, No2., 2020. pp. 174-192. 26. Boukria Oumayma, El Hadrami El Mestafa, Safarov Jasur, Boudalia Sofiane, Leriche Françoise, AïtKaddour Abderrahmane. The effect of mixing milk of different mammalian species on chemical, physicochemical, and sensory features of cheeses: a review. // Foods 2020, 9, 1309; P.1-24. doi:10.3390/foods9060724

27. Boukria Oumayma, El Hadrami El Mestafa, Sultanova Shaxnoza, Safarov Jasur, Leriche Francoise, Ait-Kaddour Abderrahmane. 2D-Cross Correlation Spectroscopy Coupled with Molecular Fluorescence Spectroscopy for Analysis of Molecular Structure Modification of Camel Milk and Cow Milk Mixtures during Coagulation. // Foods 2020, 9(6), 724; P.1-10. doi:10.3390/foods9060724 